\title{
Peculiarities of Photoluminescence in Porous Silicon Prepared by Metal-Assisted Chemical Etching
}

\author{
Igor Iatsunskyi, Valentin Smyntyna, Nykolai Pavlenko, and Olga Sviridova \\ Department of Experimental Physics, Odessa I.I.Mechnikov National University, Pastera Street 42, Odessa 65023, Ukraine \\ Correspondence should be addressed to Igor Iatsunskyi, yatsunskiy@gmail.com
}

Received 16 August 2012; Accepted 24 September 2012

Academic Editors: L. R. P. Kassab and Y. S. Kivshar

Copyright () 2012 Igor Iatsunskyi et al. This is an open access article distributed under the Creative Commons Attribution License, which permits unrestricted use, distribution, and reproduction in any medium, provided the original work is properly cited.

Photoluminescent (PL) porous layers were formed on p-type silicon by a metal-assisted chemical etching method using $\mathrm{H}_{2} \mathrm{O}_{2}$ as an oxidizing agent. Silver particles were deposited on the (100) Si surface prior to immersion in a solution of HF and $\mathrm{H}_{2} \mathrm{O}_{2}$. The morphology of the porous silicon (PS) layer formed by this method was investigated by atomic force microscopy (AFM). Depending on the metal-assisted chemical etching conditions, the macro- or microporous structures could be formed. Luminescence from metal-assisted chemically etched layers was measured. It was found that the PL intensity increases with increasing etching time. This behaviour is attributed to increase of the density of the silicon nanostructure. It was found the shift of PL peak to a green region with increasing of deposition time can be attributed to the change in porous morphology. Finally, the PL spectra of samples formed by high concentrated solution of $\mathrm{AgNO}_{3}$ showed two narrow peaks of emission at 520 and $550 \mathrm{~nm}$. These peaks can be attributed to formation of $\mathrm{AgF}$ and $\mathrm{AgF}_{2}$ on a silicon surface.

\section{Introduction}

The indirect band-gap structure of silicon strongly restricts its application in the area of optoelectronics. The indirect transition that requires the participation of phonons leads to the low radiative recombination efficiency and the poor luminescence property. Many efforts have been carried out to solve this physical inability. One of the possible candidate systems is silicon nanostructures such as porous silicon (PS) $[1,2]$, silicon nanocrystallines (SiNCs) [3-5], and silicon nanowires (SiNWs) $[6,7]$. The remarkable characteristics of visible photoluminescence (PL) in porous silicon at room temperature have given great impulse to these material studies [8-10].

PL from porous silicon is observable at wavelengths ranging from ultraviolet to the infrared. PS prepared using the electrochemical method shows strong visible emission, which is considered to originate from the quantum wires in the samples. The color of luminescence light could be well controlled by the variation of the size of the SiNCs. Various mechanisms, such as quantum confinement effect, surface state, and defect-center luminescence, were proposed to uncover the luminescence origins of PS and SiNCs. It is now generally agreed that various mechanisms are responsible for the different PL bands [11, 12].

Recently, a new method, termed metal-assisted chemical etching, has been developed, which is relatively simple compared to the electrochemical method. The method does not need an external bias and enables a formation of uniform PS layers more rapidly than the conventional stain etching method. Thin metallic films or particles (Au, Pt, Al, Pd, etc.) are generally deposited directly on a silicon surface prior to immersion in an etchant composed of HF and an oxidizing agent $[13,14]$. Metal-assisted chemical etching is essentially a wet etching method yet produces anisotropic high aspect ratio semiconductor micro and nanostructures without incurring lattice damage. These high aspect ratio structures can potentially be used for the formation of periodic nanostructures for photonic crystals, light-trapping structures for LEDs and solar cells with better absorption and collection efficiency, and in other applications.

In present paper, we report on the formation of visiblelight-emitting layers on porous p-type silicon using $\mathrm{H}_{2} \mathrm{O}_{2}$ as an oxidizing agent and silver ( $\mathrm{Ag})$ as deposited metal. 


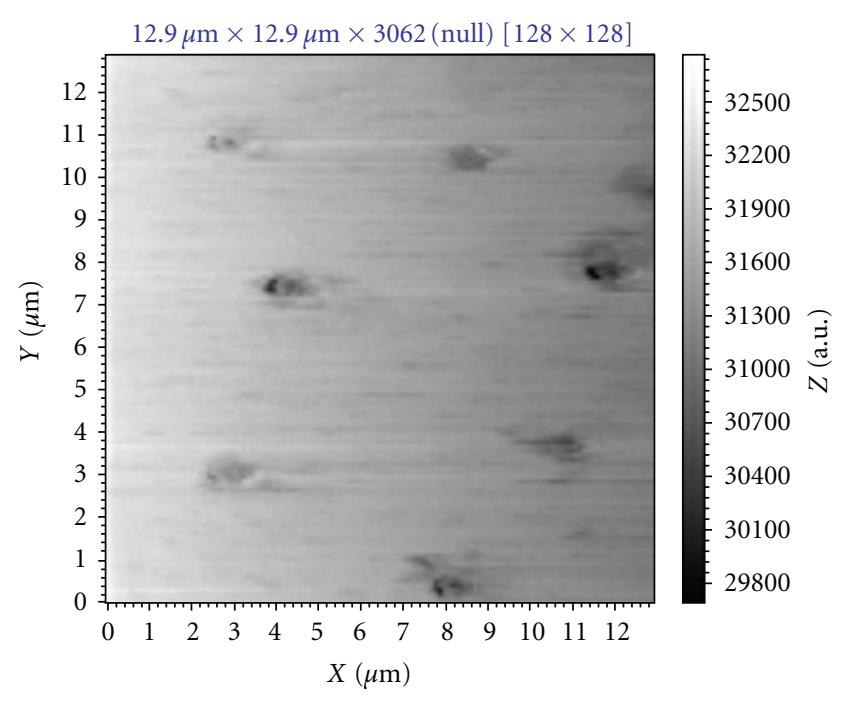

FIGURE 1: AFM image of $\mathrm{Si}(100)$ with a resistivity of $100 \mathrm{Ohm} \cdot \mathrm{cm}$ after 10 minutes etching in solution $-\mathrm{H}_{2} \mathrm{O}_{2} / \mathrm{H}_{2} \mathrm{O} / \mathrm{HF}=10 / 80 / 40$. Ag particles were deposited before etching in solution $0.23 \mathrm{M} \mathrm{HF}$ and $5 \times 10^{-5} \mathrm{M} \mathrm{AgNO}_{3}$ within $15 \mathrm{~min}$.

We discuss the etching time dependence on the morphology of PS layers and the PL peak intensity. The changes in the PL spectrum are attributed to the structural modifications of PS layers caused by etching procedure. Besides, we have observed two narrow PL peaks, which can be associated with formation of new phase or material.

\section{Experimental Procedure}

Metal-assisted chemical etching (MaCE) is fundamentally a wet etch technique. MaCE was first used as an electroless etching technique to produce porous Si and porous III$\mathrm{V}$ compound semiconductor by $\mathrm{Li}$ et al. in 2000 and 2002 , respectively $[15,16]$, in contrast to the conventional anodic etching method for porous semiconductor formation. Details on the MaCE mechanism and development can be found elsewhere $[17,18]$.

The metal-assisted chemical etching processes were applied to p-type Si wafers Czochralski-grown (100) 100 $\mathrm{Ohm} \cdot \mathrm{cm}$. After standard RCA cleaning, the wafers were cleaned with acetone and deionized water via ultrasonic cleaning. A thin oxide layer was formed, and the surface became hydrophilic. This oxide layer was removed by dipping the samples into a dilute HF solution. The silver particles, which act as catalysts to assist the etching of silicon, were deposited on Si samples by immersion in $0.23 \mathrm{M}$ $\mathrm{HF}$ and $5 \times 10^{-5} \mathrm{M} \mathrm{AgNO}_{3}$ (samples series no. 1) and in $0.23 \mathrm{M} \mathrm{HF}$ and $10^{-3} \mathrm{M} \mathrm{AgNO}_{3}$ (samples series no. 2) metallization aqueous solutions. The time of immersion was varied between 0.5 to 30 minutes. After the electroless metallization, the wafers were etched in aqueous solutions containing $\mathrm{HF}(40 \%), \mathrm{H}_{2} \mathrm{O}_{2}(30 \%)$, and ultrapure $\mathrm{H}_{2} \mathrm{O}$ at different concentration ratios and for etching times varied from 1 to 30 minutes. After etching, the samples were rinsed

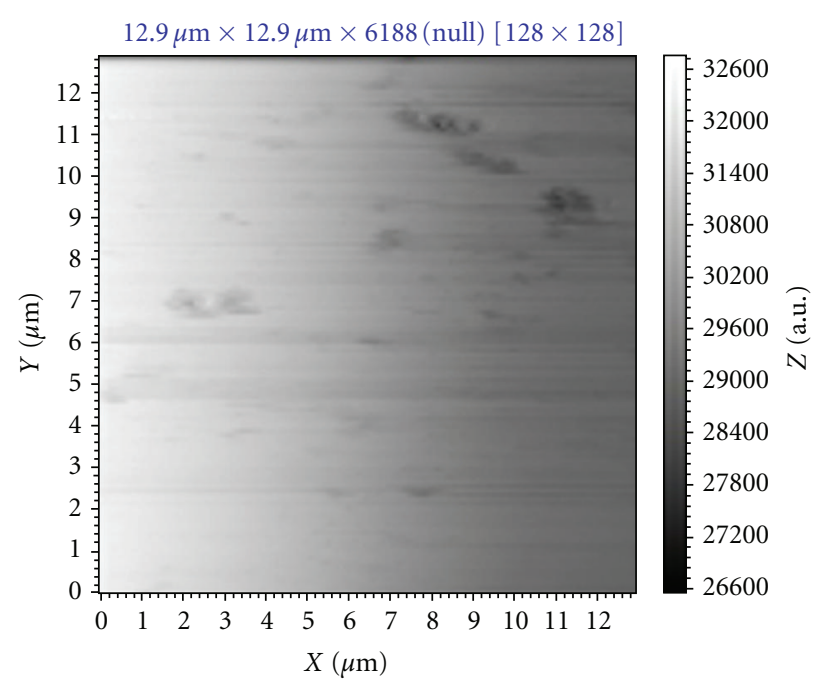

FIgURE 2: AFM image of $\mathrm{Si}(100)$ with a resistivity of $100 \mathrm{Ohm} \cdot \mathrm{cm}$ after 10 minutes etching in solution $-\mathrm{H}_{2} \mathrm{O}_{2} / \mathrm{H}_{2} \mathrm{O} / \mathrm{HF}=10 / 80 / 40$. Ag particles were deposited before etching in solution $0.23 \mathrm{M} \mathrm{HF}$ and $5 \times 10^{-5} \mathrm{M} \mathrm{AgNO}_{3}$ within $1 \mathrm{~min}$.

with deionized water. The etching and immersion procedures were performed at room temperature.

Structural properties of porous silicon prepared by metal-assisted chemical etching have been investigated by Atomic Force Microscope (AFM) NT-206. AFM studies were done at atmospheric conditions. Using AFM, we could characterize the shape and sizes of isolated particles, their distribution depending on the chemicals conditions.

The luminescence was stimulated by UV laser LCS-DTL$374 \mathrm{QT}$ with excitation wavelength $\lambda=355 \mathrm{~nm}$. The emission spectra were amplified and recorded in the wavelength range $400-900 \mathrm{~nm}$. The PL spectra were measured at room temperature.

\section{Results and Discussion}

3.1. AFM Studies of Porous Silicon. During the experiment, we obtained samples with different surface morphology. Figure 1 displays an AFM image of the porous silicon surface (samples series no. 1). At a low concentration of oxidizing agent $-\mathrm{H}_{2} \mathrm{O}_{2}\left(\mathrm{H}_{2} \mathrm{O}_{2} / \mathrm{H}_{2} \mathrm{O} / \mathrm{HF}=10 / 80 / 40\right)$, as seen from this image, there were pores that had a conical form, like a crater, having approximately the same size and uniformly distributed over its surface. The approximate diameter of pores ranged from 1 to $1.6 \mathrm{um}$ in diameter. This morphology is quite different from that observed on metal-assisted chemically etched PS obtained on high-resistivity silicon with 22.5 M HF-0.05 $\mathrm{M} \mathrm{Na}_{2} \mathrm{~S}_{2} \mathrm{O}_{8}-\mathrm{H}_{2} \mathrm{O}$ solution [19].

In the case of low deposition times, the Ag particles were deposited nonuniformly. Distribution of pores on the surface and form are not orderly, as evident in the AFM image shown in Figure 2.

The next step was to figure out how the increasing of oxidant concentration affects surface morphology. The increase 

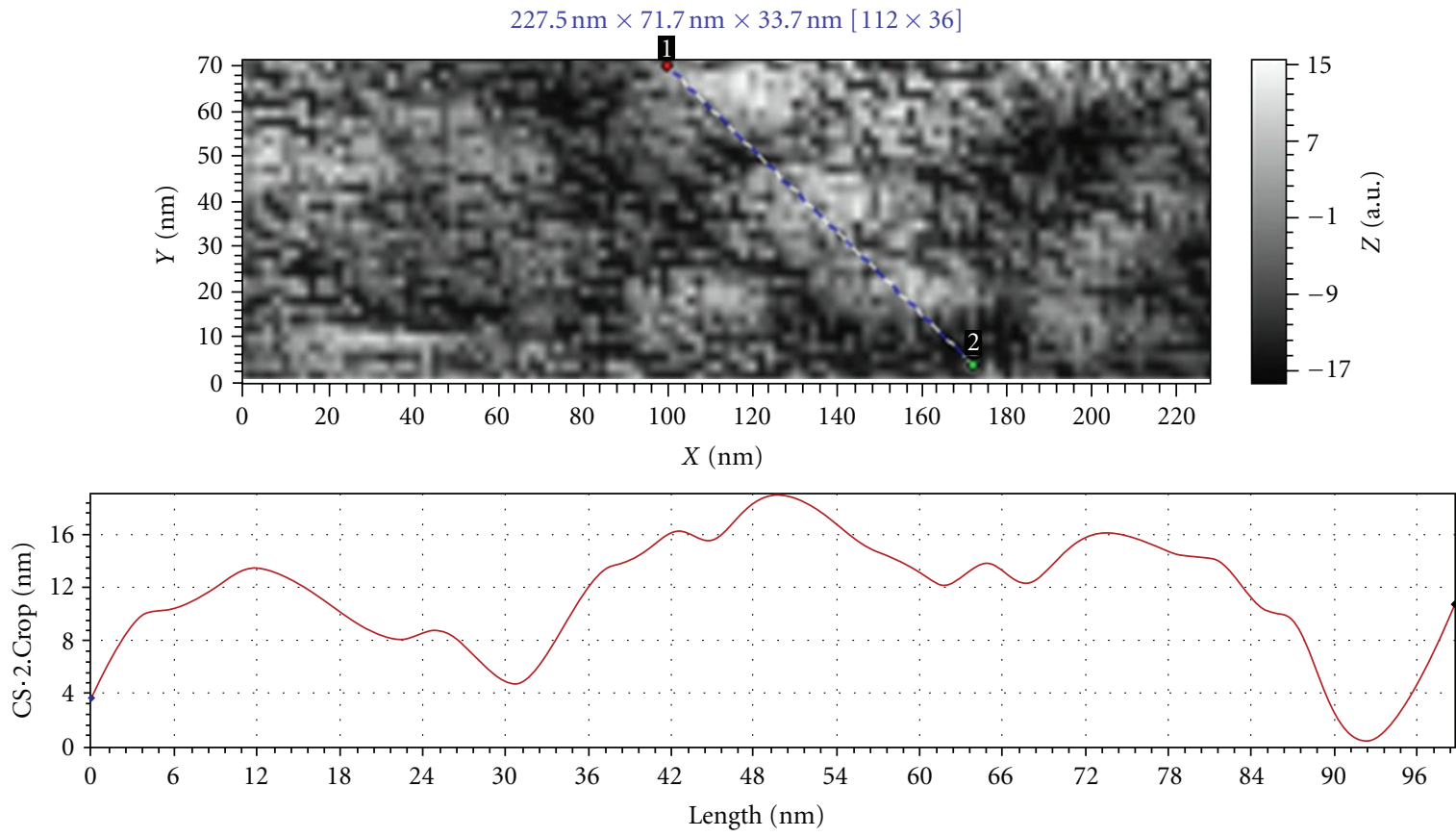

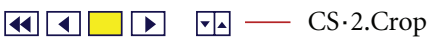

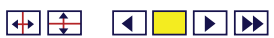

Absolute values: (a) $\geq x=0 \mathrm{~nm} ; z(1)=3.6 \mathrm{~nm} ; \quad$ (b) $\geq x=98.6 \mathrm{~nm} ; z(1)=10.8 \mathrm{~nm}$

Difference between markers: $d x=98.6 \mathrm{~nm} ; d z(1)=7.2 \mathrm{~nm}$

Difference between first two lines: $x(\mathrm{a})=0 \mathrm{~nm}, d z(\mathrm{a})=0 \mathrm{~nm} ; x(\mathrm{~b})=98.6 \mathrm{~nm}, d z(\mathrm{~b})=0 \mathrm{~nm}$

FIGURE 3: AFM image of $\mathrm{Si}(100)$ with a resistivity of $100 \mathrm{Ohm} \cdot \mathrm{cm}$ after 10 minutes etching in solution- $\mathrm{H}_{2} \mathrm{O}_{2} / \mathrm{H}_{2} \mathrm{O} / \mathrm{HF}=25 / 80 / 40$. Ag particles were deposited before etching in solution $0.23 \mathrm{M} \mathrm{HF}$ and $5 \times 10^{-5} \mathrm{M} \mathrm{AgNO}_{3}$ within 15 min.

of oxidant concentration $\left(\mathrm{H}_{2} \mathrm{O}_{2} / \mathrm{H}_{2} \mathrm{O} / \mathrm{HF}=25 / 80 / 40\right)$ leads to a change in the surface structure of silicon from microporous to highly porous structure. We have observed highly porous structure with the dimensions of the pores having an approximate size of 50-200 $\mathrm{nm}$ depending on the deposition time (Figure 3). For both concentrations of $\mathrm{H}_{2} \mathrm{O}_{2}$, the prolonged etching time induces an increase of pore depth. The changing of surface morphology due to increasing of $\mathrm{H}_{2} \mathrm{O}_{2}$ concentration could be explained by the theory proposed by Chartier et al. [20]. Charties et al. have shown that as the composition varies from high to low $\mathrm{HF} / \mathrm{H}_{2} \mathrm{O}_{2}$ ratio, mesopores, cone-shaped macropores, craters could be obtained. This change occurred because of fast dissolving of the silicon surface.

For samples series no. 2, that had higher concentration of $\mathrm{AgNO}_{3}$ in immersion solution $\left(10^{-3} \mathrm{M}\right)$, we have obtained more remarkable experimental results. The color of the silicon surface after etching has been almost black (1-15 minutes of immersion time) or light brown (15-30 minutes of immersion time) depending on the immersion time. First, we supposed that it is similar to "black" silicon having a needleshaped surface structure where needles are made of singlecrystal silicon and have a height above 10 microns and diameter less than 1 micron [21]. However, AFM investigation showed an absolutely other morphology (Figure 4) having macropores.
The macropores grow parallel and perpendicular to the surface, a result similar to that generally observed on $\mathrm{p}$ type highly resistive silicon electrochemically etched [22]. It is remarkable that as the concentration of $\mathrm{AgNO}_{3}$ increases the diameter of pores is increased. An intensive process of silver particle deposition can explain this phenomenon. As far as the surface color, the formation of new compounds like $\mathrm{AgF}$ (silver fluoride) and $\mathrm{AgF}_{2}$ (silver difluoride) on the surface with appropriate colors-AgF (light brown), $\mathrm{AgF}_{2}$ (dark brown) can explain given experimental observations. We have found these compounds onto the surface using XFS measurement (not shown here). Following reactions show how the compound's formation could occur:

$$
\begin{gathered}
\mathrm{Ag}+2 \mathrm{HF}+\mathrm{H}_{2} \mathrm{O}_{2} \longrightarrow 2 \mathrm{AgF}+2 \mathrm{H}_{2} \mathrm{O} \\
\mathrm{Ag}+2 \mathrm{~F} \longrightarrow \mathrm{AgF}_{2}
\end{gathered}
$$

It was obvious that the transition of morphology from microporous to macroporous structure would modify the optical properties of the silicon surface. It was indeed observed in luminescence properties of silicon porous structure.

3.2. PL Characteristics of Porous Silicon. Figure 5 shows PL spectra from samples series no. 1 etched for 6 minutes 


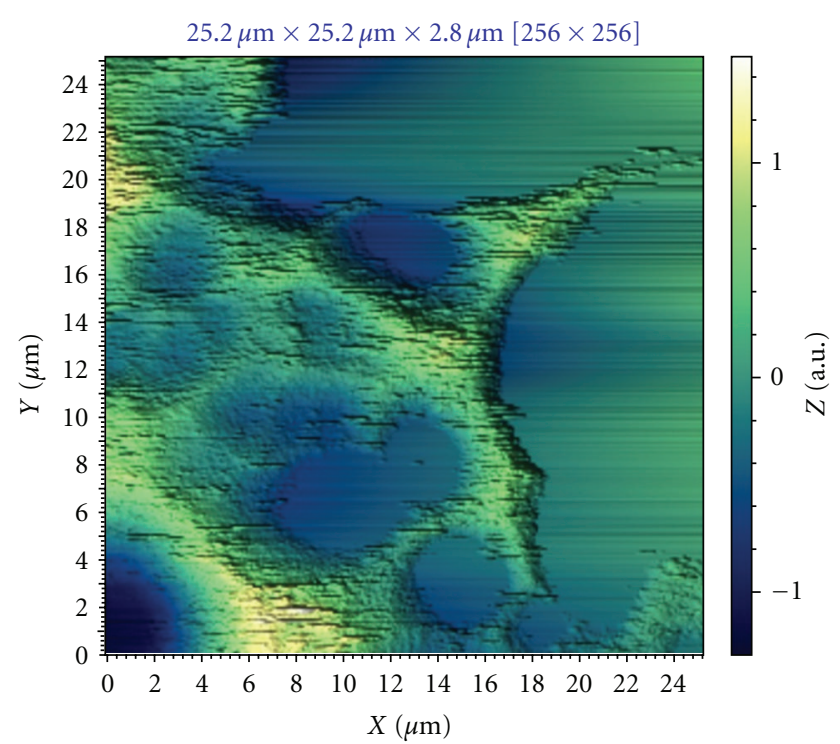

FIGURE 4: AFM image of $\mathrm{Si}(100)$ with a resistivity of $100 \mathrm{Ohm} \cdot \mathrm{cm}$ after 15 minutes etching in solution $-\mathrm{H}_{2} \mathrm{O}_{2} / \mathrm{H}_{2} \mathrm{O} / \mathrm{HF}=15 / 80 / 40$. $\mathrm{Ag}$ particles were deposited before etching in solution $0.23 \mathrm{M} \mathrm{HF}$ and $10^{-3} \mathrm{M} \mathrm{AgNO}_{3}$ within $15 \mathrm{~min}$.

in the concentration etchant $\left(\mathrm{H}_{2} \mathrm{O}_{2} / \mathrm{H}_{2} \mathrm{O} / \mathrm{HF}=10 / 80 / 40\right)$. The deposition time varied from 1 to 10 minutes. There was a correlation between PL spectra and the metal-assisted chemical etching conditions. The PL could not be observed if the deposition time was less than 1 minute. The PL spectra had approximately Gaussian line shapes. The PL intensity is significantly increased by surface etching and deposition time, while the PL spectrum remains almost unchanged. This fact can be related to the increase of the silicon porous density, that is, of radiative recombination centers. The PL spectra present emission peaks centered at approximately $680-700 \mathrm{~nm}$ (corresponding energies $1.77-1.82 \mathrm{eV}$ ). These peaks correspond to emission in the red region.

Figure 6 shows the PL spectra for three samples of porous silicon etched for 6 minutes, but prepared in a more concentrated solution of hydrogen peroxide etchant $\left(\mathrm{H}_{2} \mathrm{O}_{2} / \mathrm{H}_{2} \mathrm{O} / \mathrm{HF}=25 / 80 / 40\right)$. The deposition time varied from 0.5 to 6 minutes. It can be noticed the shifting of luminescence peaks to shorter wavelengths of the spectrum (to be higher energies) due to increasing of deposition time. It is also seeing an increase in PL intensity. The PL spectra present emission peaks centered at 620,610 , and $560 \mathrm{~nm}$ (corresponding energies 1.99, 2.03, $2.21 \mathrm{eV}$ ), respectively.

Besides, it can be seen the complex shape of the PL curve. By Origin pro 8.5 software, the PL spectrum was split onto separate peaks (Figure 7). The PL peaks located at 480, 550 , and $670 \mathrm{~nm}$ have been found. The full explanation of photoluminescence has not been done yet. The PL peak at the red region is well understood based on the quantumconfinement model [23]. The PL peak at green region is supposed associated with formation of $\mathrm{AgF}$ or $\mathrm{AgF}_{2}$. The microscopic origin of the wide blue luminescence band in the given porous $\mathrm{Si}$ has to date not been convincingly established,

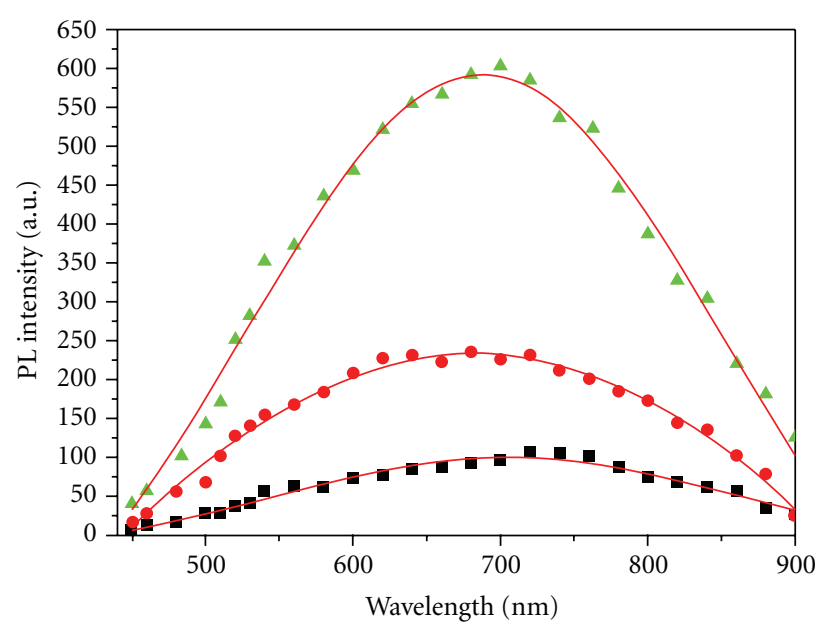

- Deposition time $1 \mathrm{~min}$

- Deposition time $5 \mathrm{~min}$

$\triangle$ Deposition time $10 \mathrm{~min}$

Figure 5: Photoluminescence spectra as a function of the deposition time taken from Ag-assisted chemically etched silicon. Etching was performed in solution- $\mathrm{H}_{2} \mathrm{O}_{2} / \mathrm{H}_{2} \mathrm{O} / \mathrm{HF}=10 / 80 / 40$ within $10 \mathrm{~min}$. Ag particles were deposited before etching in solution $0.23 \mathrm{M} \mathrm{HF}$ and $5 \times 10^{-5} \mathrm{M} \mathrm{AgNO}_{3}$.

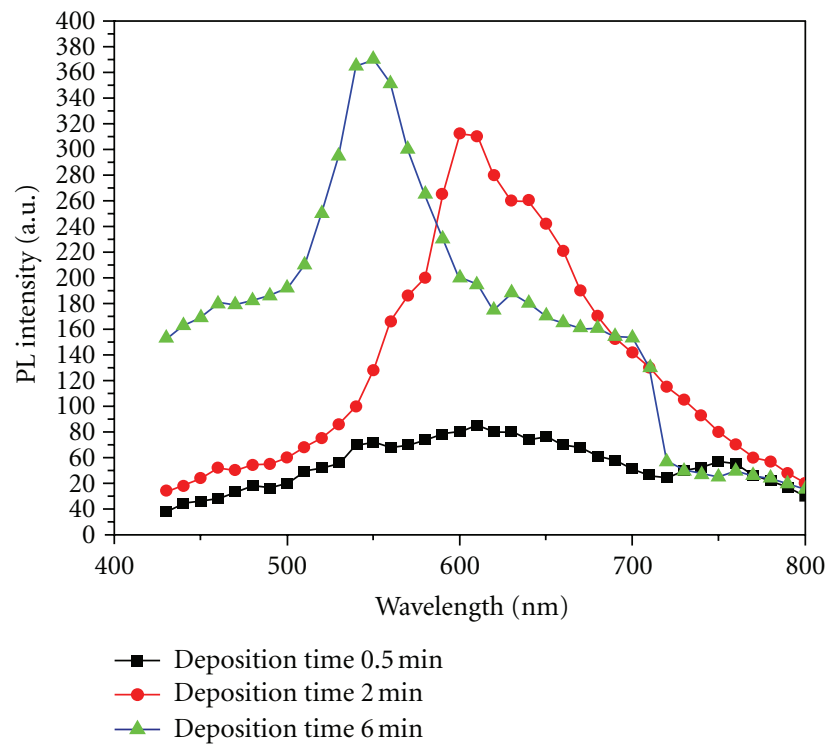

FIGURE 6: Photoluminescence spectra as a function of the deposition time taken from Ag-assisted chemically etched silicon. Etching was performed in solution $-\mathrm{H}_{2} \mathrm{O}_{2} / \mathrm{H}_{2} \mathrm{O} / \mathrm{HF}=25 / 80 / 40$ within $6 \mathrm{~min}$. Ag particles were deposited before etching in solution $0.23 \mathrm{M}$ $\mathrm{HF}$ and $5 \times 10^{-5} \mathrm{M} \mathrm{AgNO}_{3}$.

and additional measurements will be performed in future works.

The next stage of the experiment was to investigate the photoluminescence spectra for samples series no. 2 $\left(\mathrm{M}\left(\mathrm{AgNO}_{3}\right)=10^{-3} \mathrm{M}\right)$ etched for 6 minutes in the concentration etchant $\left(\mathrm{H}_{2} \mathrm{O}_{2} / \mathrm{H}_{2} \mathrm{O} / \mathrm{HF}=15 / 80 / 40\right)$. The PL spectra present three emission peaks centered at 520, 550, 


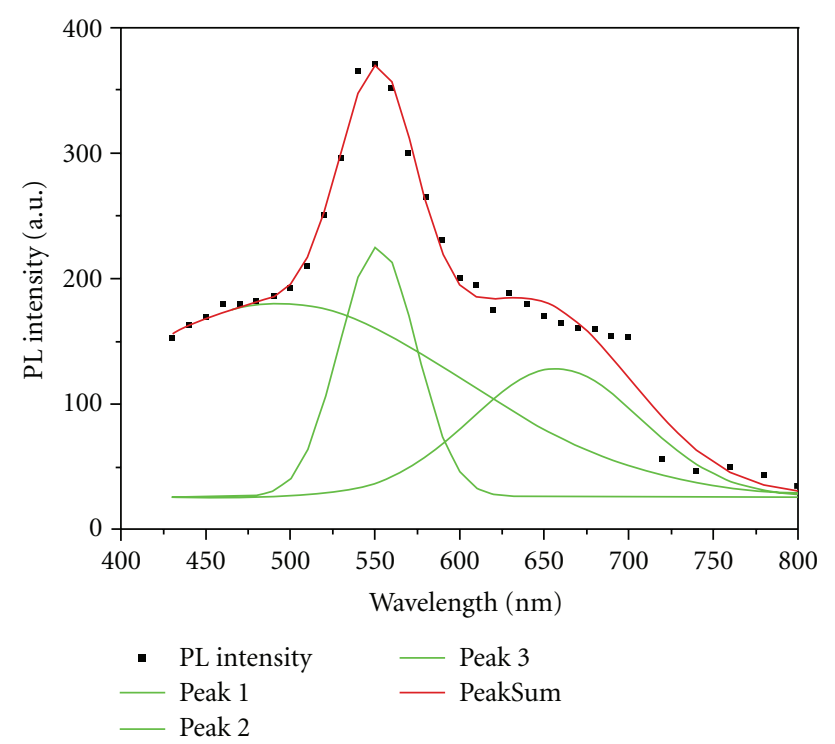

Figure 7: Photoluminescence spectrum of highly porous silicon. Etching was performed in solution $-\mathrm{H}_{2} \mathrm{O}_{2} / \mathrm{H}_{2} \mathrm{O} / \mathrm{HF}=25 / 80 / 40$ within $6 \mathrm{~min}$. Deposition time- $6 \mathrm{~min}$ in solution $0.23 \mathrm{M} \mathrm{HF}$ and $5 \times 10^{-5} \mathrm{M} \mathrm{AgNO}_{3}$.

and $710 \mathrm{~nm}$, respectively (Figure 8). The first and second peaks are more intense and correspond to emission in the green region; on the other hand, the third peak situated in the red region is less powerful. The intensity of the two peaks intensity increases with etching time. Comparing the data with the energy band gap of fluoride and difluoride, silver (in the theoretical studies presented data are in the range $2-2.8 \mathrm{eV}$ ), we can assume that the peak falls at $550 \mathrm{~nm}$ corresponds to the silver difluoride, and the peak of $520 \mathrm{~nm}$-silver fluoride [24-26].

The red peak in Figure 8, observed in sample series no. 1 as well, is associated with nanostructured silicon, the socalled S-band [27]. According to the quantum confinement model, the emission wavelength and the PL peak intensity are correlated to nanocrystallite size and the number (density) of nanocrystallites, respectively [28]. Thus, we can conclude that the sizes of nanocrystallites of the sample series no. 1 are smaller compared to those of samples series no. 2. It seems that when the silver concentration in immersion solution becomes lower the nanocrystallite size decreases leading to a shift of PL peak to the shorter wavelengths.

This result is very interesting, since it is difficult to form light-emitting porous layers on highly resistive silicon by the electrochemical method. Porous silicon layers exhibit strong red luminescence with PL peaks ranged within 630$680 \mathrm{~nm}$, which are similar to those found for medium doped anodically etched silicon [1]. It is also important to note that the PL spectrum peaks of sample series no. 2 are not perfectly Gaussian. Since the visible luminescence spectra of common PS had a shape close to a Gaussian curve, the assumption that the luminescence spectrum, for these samples, can be fitted by addition of several Gaussian curves (peaks) is appropriate. Indeed, Figure 7 shows that it can

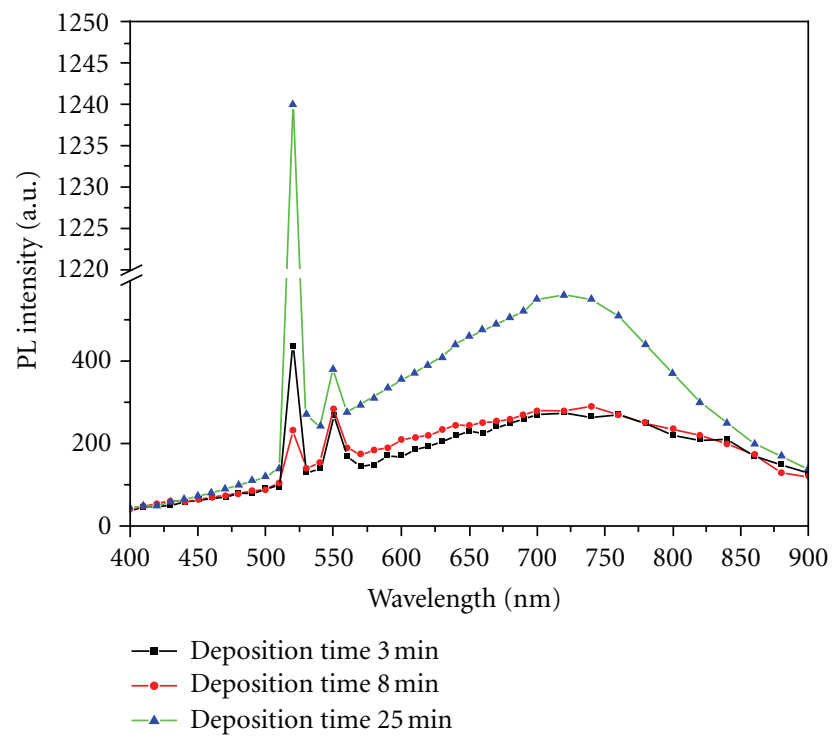

Figure 8: Photoluminescence spectra as a function of the deposition time taken from Ag-assisted chemically etched silicon. Etching was performed in solution $-\mathrm{H}_{2} \mathrm{O}_{2} / \mathrm{H}_{2} \mathrm{O} / \mathrm{HF}=15 / 80 / 40$ within $6 \mathrm{~min}$. Ag particles were deposited before etching in solution $0.23 \mathrm{M}$ $\mathrm{HF}$ and $10^{-3} \mathrm{M} \mathrm{AgNO}_{3}$.

be fitted by a sum of three Gaussian curves. These results differ from those found by Hadjersi et al., where only two PL peaks were centered at 617 and $646 \mathrm{~nm}$ [29]. This is most likely due to preparation conditions of samples that have produced a morphology different from that of our samples. Indeed, they used an etching solution of $\mathrm{HF}$ and $\mathrm{Na}_{2} \mathrm{~S}_{2} \mathrm{O}_{8}$. This confirms that different morphologies can be produced by varying the type of etchant solution. In addition, the significant result obtained is the observation of two narrow PL peaks centered at 520 and $550 \mathrm{~nm}$. These peaks can be attributed to formation of $\mathrm{AgF}$ and $\mathrm{AgF}_{2}$ on a silicon surface.

\section{Conclusion}

Photoluminescence and surface morphologies of nanostructured porous silicon prepared by metal-assisted chemical etching using $\mathrm{H}_{2} \mathrm{O}_{2}$ as an oxidizing agent have been studied. Depending on the metal-assisted chemical etching conditions, the macro- or microporous structures could be formed. Red band emissions were observed at $680-700 \mathrm{~nm}$ for silicon microporous structure. For highly porous silicon structures, we have observed PL peaks at 620,610, and $560 \mathrm{~nm}$. It was shown that the PL intensity increases with increasing etching time, which can be attributed to the increase of the silicon nanostructure density in agreement with the quantum confinement model prediction. It was found the shift of red PL peak to a green region with increasing of deposition time that can be attributed to the changing in porous morphology. The PL spectra of samples prepared with high concentrated solution of $\mathrm{AgNO}_{3}$ present two narrow peaks centered at 520 and $550 \mathrm{~nm}$. These peaks can be attributed to formation of $\mathrm{AgF}$ and $\mathrm{AgF}_{2}$ on a silicon surface. 


\section{References}

[1] L. T. Canham, "Silicon quantum wire array fabrication by electrochemical and chemical dissolution of wafers," Applied Physics Letters, vol. 57, Article ID 1046, 1990.

[2] B. Gelloz, A. Kojima, and N. Koshida, "Highly efficient and stable luminescence of nanocrystalline porous silicon treated by high-pressure water vapor annealing," Applied Physics Letters, vol. 87, Article ID 031107, 2005.

[3] N. A. Hill and K. B. Whaley, "Size dependence of excitons in silicon nanocrystals," Physical Review Letters, vol. 75, pp. 1130-1133, 1995.

[4] P. Mutti, G. Ghislotti, S. Bertoni et al., "Room-temperature visible luminescence from silicon nanocrystals in silicon implanted $\mathrm{SiO}_{2}$ layers," Applied Physics Letters, p. 851, 1995.

[5] G. Sahu, H. P. Lenka, D. P. Mahapatra, B. Rout, and F. D. McDaniel, "Narrow band UV emission from direct bandgap Si nanoclusters embedded in bulk Si," Journal of Physics, vol. 22, no. 7, Article ID 072203, 2010.

[6] M. W. Shao, L. Cheng, M. L. Zhang et al., "Nitrogen-doped silicon nanowires: Synthesis and their blue cathodoluminescence and photoluminescence," Applied Physics Letters, vol. 95, Article ID 143110, 2009.

[7] J. Huo, R. Solanki, J. L. Freeouf, and J. R. Carruthers, "Electroluminescence from silicon nanowires," Nanotechnology, vol. 15, no. 12, pp. 1848-1850, 2004.

[8] B. C. Chakravarty, J. Tripathi, A. K. Sharma et al., "The growth kinetics and optical confinement studies of porous Si for application in terrestrial Si solar cells as antireflection coating," Solar Energy Materials and Solar Cells, vol. 91, no. 8, pp. 701706, 2007.

[9] T. Torchynska, J. Aguilar-Hernandez, M. Morales Rodriguez et al., "Comparative investigation of photoluminescence of silicon wire structures and silicon oxide films," Journal of Physics and Chemistry of Solids, vol. 63, no. 4, pp. 561-568, 2002.

[10] H. S. Mavi, B. G. Rasheed, A. K. Shukla, S. C. Abbi, and K. P. Jain, "Photoluminescence study of Nd:YAG laser-etched silicon," Journal of Non-Crystalline Solids, vol. 286, no. 3, pp. 162-168, 2001.

[11] N. Tit, Z. H. Yamani, G. Pizzi, and M. Virgilio, "Origins of visible-light emissions in porous silicon," Physica Status Solidi C, vol. 9, pp. 1458-1461, 2012.

[12] L. H. Lin, X. Z. Sun, R. Tao et al., "Photoluminescence origins of the porous silicon nanowire arrays," Journal of Applied Physics, vol. 110, Article ID 073109, 2011.

[13] K. Balasundaram, J. S. Sadhu, J. C. Shin et al., "Porosity control in metal-assisted chemical etching of degenerately doped silicon nanowires," Nanotechnology, vol. 23, no. 30, Article ID 305304, 2012.

[14] Y. Harada, X. Li, P. W. Bohn, and R. G. Nuzzo, "Catalytic amplification of the soft lithographic patterning of Si. Nonelectrochemical orthogonal fabrication of photoluminescent porous Si pixel arrays," Journal of the American Chemical Society, vol. 123, no. 36, pp. 8709-8717, 2001.

[15] X. Li and P. W. Bohn, "Metal-assisted chemical etching in $\mathrm{HF} / \mathrm{H}_{2} \mathrm{O}_{2}$ produces porous silicon," Applied Physics Letters, vol. 77, Article ID 2572, 2000.

[16] X. Li, Y. W. Kim, P. W. Bohn, and I. Adesida, "In-plane bandgap control in porous GaN through electroless wet chemical etching," Applied Physics Letters, vol. 80, no. 6, p. 980, 2002 .
[17] Z. Huang, N. Geyer, P. Werner, J. De Boor, and U. Gösele, "Metal-assisted chemical etching of silicon: a review," Advanced Materials, vol. 23, no. 2, pp. 285-308, 2011.

[18] W. K. Kolasinski, "Silicon nanostructures from electroless electrochemical etching," Current Opinion in Solid State \& Materials Science, vol. 9, pp. 73-83, 2005.

[19] T. Hadjersi, N. Gabouze, E. S. Kooij et al., "Metal-assisted chemical etching in $\mathrm{HF} / \mathrm{Na}_{2} \mathrm{~S}_{2} \mathrm{O}_{8} \mathrm{OR} \mathrm{HF} / \mathrm{KMnO}_{4}$ produces porous silicon," Thin Solid Films, vol. 459, no. 1-2, pp. 271275, 2004.

[20] C. Chartier, S. Bastide, and C. Lévy-Clément, "Metal-assisted chemical etching of silicon in $\mathrm{HF}_{-} \mathrm{H}_{2} \mathrm{O}_{2}$," Electrochimica Acta, vol. 53, no. 17, pp. 5509-5516, 2008.

[21] S. Koynov, M. S. Brandt, and M. Stutzmann, "Black nonreflecting silicon surfaces for solar cells," Applied Physics Letters, vol. 88, Article ID 203107.

[22] J. N. Chazalviel, F. Ozanam, N. Gabouze, S. Fellah, and R. B. Wehrspohn, "Quantitative analysis of the morphology of macropores on low-doped p-Si: minimum resistivity," Journal of the Electrochemical Society, vol. 149, no. 10, pp. C511-C520, 2002.

[23] C. Delerue, G. Allan, and M. Lannoo, "Theoretical aspects of the luminescence of porous silicon," Physical Review B, vol. 48, no. 15, pp. 11024-11036, 1993.

[24] J. T. Wolan and G. B. Hoflund, "Surface characterization study of $\mathrm{AgF}$ and $\mathrm{AgF}_{2}$ powders using XPS and ISS," Applied Surface Science, vol. 125, no. 3-4, pp. 251-258, 1998.

[25] B. N. Onwuagba, "The electronic structure of $\mathrm{AgF}, \mathrm{AgCl}$ and AgBr," Solid State Communications, vol. 97, no. 4, pp. 267-271, 1996.

[26] R. C. Birtcher, P. W. Deutsch, J. F. Wendelkens, and A. B. Kunz, "Valence band structure in silver fluoride," Journal of Physics C, vol. 5, p. 562, 1972.

[27] H. Mizuno, H. Koyama, and N. Koshida, "Oxide-free blue photoluminescence from photochemically etched porous silicon," Applied Physics Letters, vol. 69, no. 25, pp. 3779-3781, 1996.

[28] G. Ledoux, O. Guillois, D. Porterat et al., "Photoluminescence properties of silicon nanocrystals as a function of their size," Physical Review B, vol. 62, no. 23, pp. 15942-15951, 2000.

[29] T. Hadjersi, N. Gabouze, N. Yamamoto, H. Takai, and A. Ababou, "Photoluminescence from undoped silicon after chemical etching combined with metal plating," Physica Status Solidi C, vol. 2, pp. 3384-3388, 2005. 

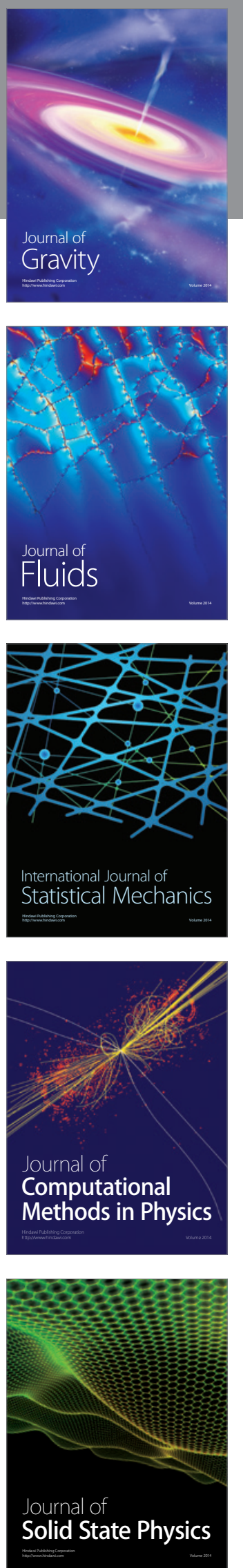
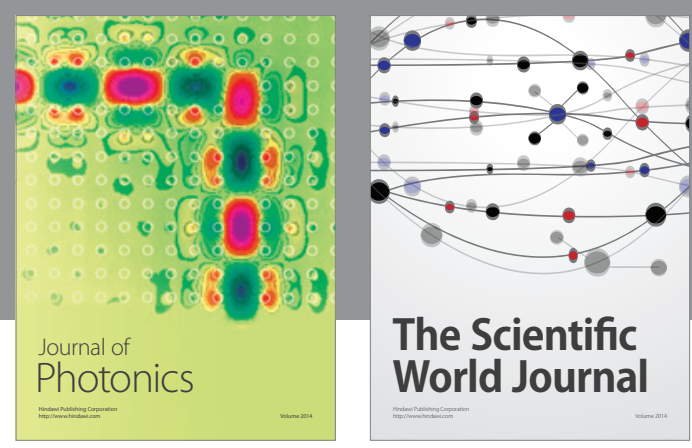

The Scientific World Journal

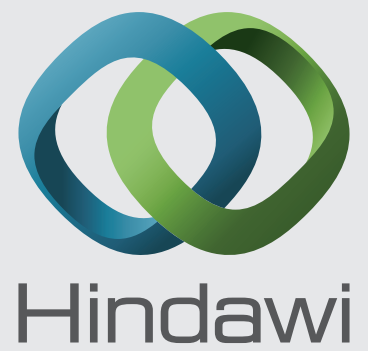

Submit your manuscripts at http://www.hindawi.com
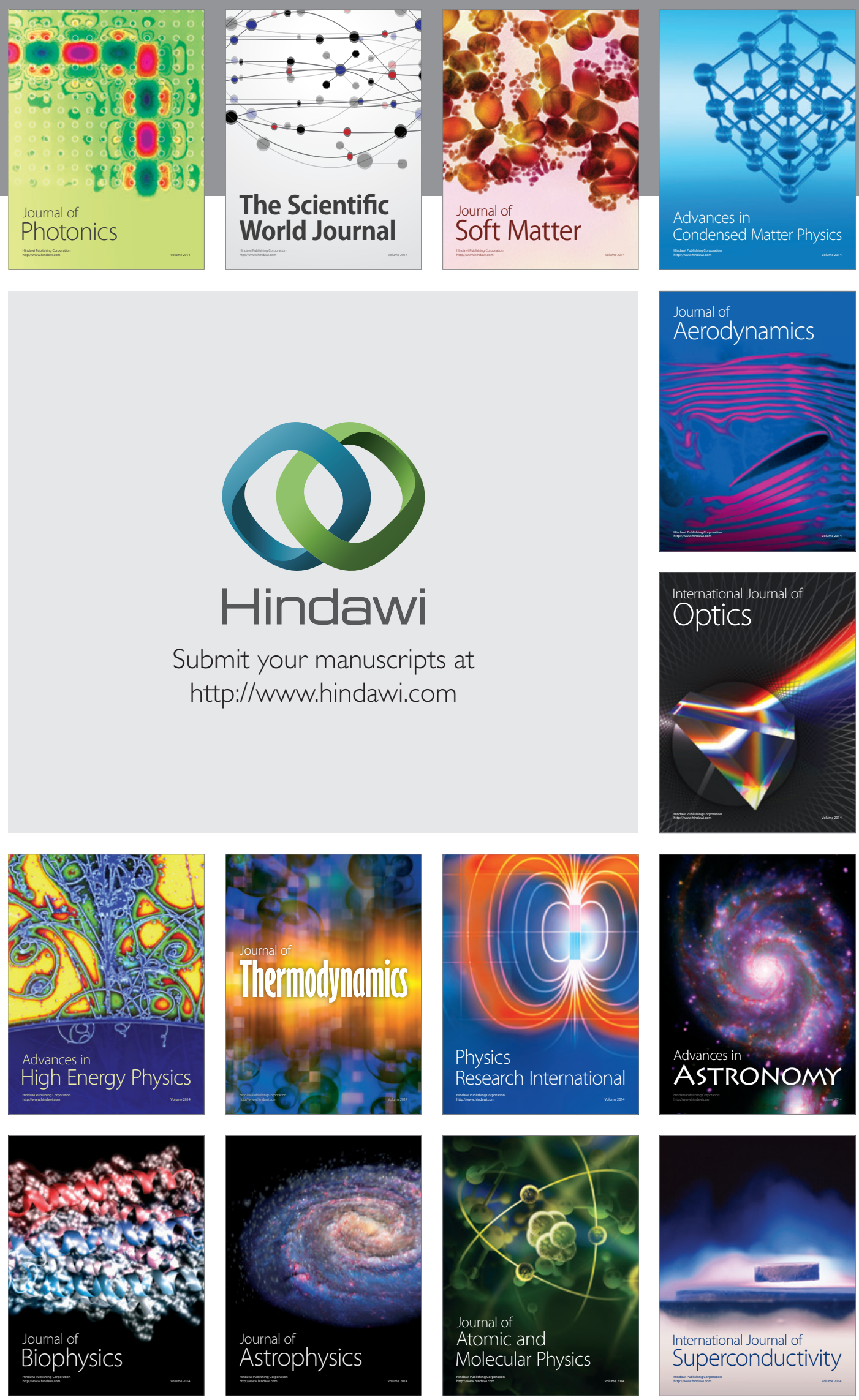
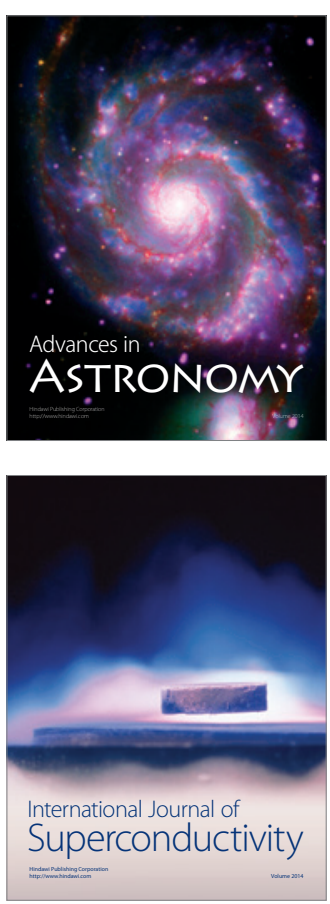